\title{
POR QUE DEBATER O ENSINO DE SOCIOLOGIA? PERSPECTIVAS DE PROFESSORES E INTELECTUAIS NO BRASIL DAS DÉCADAS DE 1930 A 1950
}

Why Discussing the Teaching of Sociology? Perspectives of Teachers and Intellectuals in Brazil from the 1930's to the 1950's

Roberta dos Reis Neuhold ${ }^{1}$

\begin{abstract}
Resumo: Este artigo constrói uma narrativa sobre a formação das Ciências Sociais como ciência e profissão no Brasil a partir dos debates que, entre as décadas de 1930 e 1950, problematizaram a sua didática. Quais fatores motivaram a participação de cientistas sociais no debate sobre o ensino de Sociologia, considerando que muitos deles sequer lecionavam no ensino secundário ou nas escolas normais? Por que debater o ensino de Sociologia nos circuitos especializados do conhecimento? Essas são indagações centrais deste trabalho que, tendo como principais fontes a produção acadêmica, biografias e depoimentos de intelectuais, aponta que, nos esforços de consolidação de um campo acadêmico, os cientistas sociais se depararam com os dilemas do magistério, alçando-os a objeto de reflexão ao lado do ensino de Sociologia e de seu papel nos bancos escolares.
\end{abstract}

Palavras-chave: Ensino de Sociologia. Intelectuais. Docência.

Abstract: This paper builds a narrative about the formation of Social Sciences as science and profession in Brazil. The focus is on the debates that, between the 1930s and 1950s, problematized the didactics of Sociology. What factors motivated the participation of social scientists in the debate about the teaching of Sociology, considering that they did not even teach in high school? Why discussing the teaching of Social Sciences in specialized circuits of knowledge? This is a fundamental question of this work which, having biographies and testimonies as sources, points out that in the efforts to consolidate an academic field, social scientists have faced the dilemmas of the teaching profession, raising them to the subject of reflection alongside teaching sociology and its role in high school.

Keyword: Teaching Sociology. Intellectuals. Teaching Practice.

\section{Introdução}

Na década de 1930, às consagradas obras dos intérpretes do Brasil somou-se uma gama de estudos que estabeleceram pontos de inflexão no pensamento social brasileiro (IANNI, 2004). Naquele momento, a preocupação com a modernização do país, cujos vestígios já se encontravam presentes na Semana de Arte Moderna de 1922, no tenentismo e em outros movimentos culturais e políticos (IANNI, 2004), ganhava projeção, exprimindo certa "[...] mentalidade de radicalismo intelectual e análise social que eclodiu depois da Revolução de

\footnotetext{
${ }^{1}$ Doutora em Educação pela Universidade de São Paulo (USP). Mestre em Sociologia pela mesma instituição. Graduada em Ciências Sociais pela USP e em Pedagogia pela Universidade Federal de São Carlos. Professora e pesquisadora da área de Ciências Sociais e da Pós-Graduação em Educação Básica e Profissional do Instituto Federal de Educação, Ciência e Tecnologia do Rio Grande do Sul. Orcid: https://orcid.org/0000-0002-1094-2398. E-mail: roberta.neuhold@alumni.usp.br
} 
1930 e não foi, apesar de tudo, abafada pelo Estado Novo" (CANDIDO, 1979, p. XI). As matrizes do pensamento sociológico convergiam, então, para as tentativas de compreender, nos termos de Otávio Ianni (2004, p. 23), “[...] dilemas básicos da sociedade nacional”, como as condições de progresso e de industrialização. Alguns desses dilemas estiveram presentes também no discurso de reconstrução educacional e prepararam o terreno para a criação dos primeiros cursos universitários de Ciências Sociais.

À época, duas vertentes se sobressaíam no debate educacional: de um lado, movimentos renovadores adeptos da Escola Nova, inspirados no processo de industrialização e urbanização e na promessa de modernização do país; de outro, a Igreja Católica, que tentava recuperar a hegemonia no campo pedagógico (SAVIANI, 2010). Alinhado à primeira vertente, o Manifesto dos Pioneiros da Educação Nova, publicado em 1932, de certa forma sistematizou as propostas de um grupo de educadores em defesa da renovação e da coesão interna do sistema educacional (SAVIANI, 2010), a despeito de suas ambiguidades associadas a um texto heterogêneo e, muitas vezes, contraditório, combinando vertentes como a liberal igualitarista, a liberal elitista, a socialista e a funcionalista durkheimiana (CUNHA, 1994; SAVIANI, 2010).

Entre outros aspectos, o Manifesto dos Pioneiros da Educação Nova criticava o ensino superior centrado nas profissões liberais, defendendo a fundação de faculdades de Ciências Sociais e Econômicas, Matemáticas, Físicas e Naturais, e de Filosofia e Letras. Aqueles novos cursos deveriam ser organizados de tal forma que desempenhassem a tríplice função de "[...] elaboradora ou criadora de ciência (investigação), docente ou transmissora de conhecimentos (ciência feita) e de vulgarizadora ou popularizadora, pelas instituições de extensão universitária, das ciências e das artes" (MANIFESTO DOS PIONEIROS DA EDUCAÇÃO, 2010, p. 56). O documento também problematizava a formação de professores, até então recrutados entre pessoas "[...] sem qualquer preparação profissional" (MANIFESTO DOS PIONEIROS DA EDUCAÇÃO, 2010, p. 59) para lecionar no ensino secundário ou entre os egressos de escolas normais que não ofereciam a necessária preparação geral e pedagógica para o magistério.

Foi justamente no contexto desse debate sobre a necessidade de formar forças culturais impulsionadoras do desenvolvimento do país que ocorreu a fundação dos primeiros cursos de graduação em Ciências Sociais: em São Paulo, na Escola Livre de Sociologia e Política (1933) e na Faculdade de Filosofia, Ciências e Letras da Universidade de São Paulo (1934); no Rio de Janeiro, na Universidade do Distrito Federal (1935); e no Paraná, na Faculdade de Filosofia, Ciências e Letras (1938). Eram os experimentos universitários pioneiros das Ciências Sociais no Brasil, salvo sua presença, desde o final do século XIX, nos cursos que graduavam bacharéis em Direito. Na verdade, alguns esboços de sua constituição já podiam ser encontrados nos museus científicos do final do século XIX e nas pesquisas etnográficas neles desenvolvidas (SCHWARCZ, 2001), bem como em estudos sobre a sociedade brasileira, mas foi mesmo a partir da década de 1930 que se formou um quadro intelectual e institucional mais sólido das Ciências Sociais no Brasil.

No bojo de tais acontecimentos, também se inseriu a Reforma Francisco Campos, que ratificou a permanência da Sociologia como disciplina do ensino secundário, com o intuito de implementar uma política de abrangência nacional. Anos antes, a Reforma João Luiz Alves/Rocha Vaz (Decreto $n^{\circ}$ 16.782-A/1925) já havia tornado a Sociologia uma disciplina das turmas do sexto ano do ensino secundário, mas a legislação só abarcava as escolas do Distrito Federal. A partir de 1928, ela passou a integrar a matriz curricular das escolas normais na perspectiva de conferir cientificidade à formação de professores que se dedicariam à educação primária (MEUCCI, 2000). Ali seria mantida durante décadas, sobretudo na forma de Sociologias especializadas, como Sociologia Educacional, Sociologia da Educação, Fundamentos de Sociologia, Investigações Sociais em nosso Meio, entre outras. 
Este artigo retoma os resultados de uma investigação ${ }^{2}$ sobre a participação do meio científico e acadêmico no debate sobre a constituição da Sociologia como disciplina escolar para organizar acontecimentos da história das Ciências Sociais raramente abordados - ou costumeiramente silenciados - nos estudos sobre o pensamento social brasileiro: os dilemas e perspectivas que perpassam o ensino da Sociologia, particularmente no contexto escolar. $\mathrm{O}$ tema, como tantos outros condizentes ao campo escolar relegados aos pesquisadores da área da Educação (BOURDIEU, 1991; MORAES, 2003), gozou de certo prestígio entre cientistas sociais, nas décadas de 1930 a 1950 (NEVES, 2002). Não à toa, aquele período é recuperado para analisar as motivações dos intelectuais para discutirem o ensino de Sociologia nos circuitos especializados do conhecimento. Trabalha-se, assim, com a perspectiva de que não se tratava de objeto inexistente, mas, antes, retomando Pierre Bourdieu (2010), de um objeto entendido como indigno e, com isso, sujeito ao silenciamento. Ou, ainda, nos termos de Irene Cardoso (2000), de uma narrativa construída a partir de acontecimentos desaparecidos, não enunciados, mas nem por isso não traduzíveis em objetos pensáveis.

Constrói-se, de certa forma, uma narrativa sobre as Ciências Sociais, costurando biografias e depoimentos de intelectuais que problematizaram a didática das e nas Ciências Sociais, entre as décadas de 1930 e 1950. Priorizaram-se fontes primárias formadas por textos de autoria desses próprios intelectuais, em uma pesquisa documental que percorreu os anos de 1939 a 1955. Entre as principais fontes, encontra-se a revista Sociologia, com particular interesse pelos primeiros 12 volumes e 46 números da fase "didática" do periódico, em alusão à sua autodenominação como "revista didática e científica"; os anais do $1^{\circ}$ Congresso Brasileiro de Sociologia realizado em São Paulo em 1954; e textos biográficos de Antonio Candido, Donald Pierson, Emilio Willems e Florestan Fernandes, entre outros autores cujas trajetórias acadêmicas e profissionais forneceram pistas para compreender o interesse dos intelectuais pelo ensino de Sociologia. A legislação educacional e as atas e estatutos da Sociedade Brasileira de Sociologia constituíram fontes complementares de consulta. Após levantamento, seleção e organização, os materiais foram sistematizados e analisados a partir de uma abordagem qualitativa, ao lado de um esforço de revisão bibliográfica que trouxe tanto substrato teórico quanto apoio à dimensão metodológica.

O artigo inicia com um panorama da participação, direta ou indireta, de cientistas sociais na discussão ou mesmo na formação da Sociologia como disciplina escolar. Entre eles estão Florestan Fernandes, Fernando de Azevedo, Gilberto Freyre, Roger Bastide, Donald Pierson, Emilio Willems, Herbert Baldus e Antonio Candido. E quais foram as motivações desses intelectuais para participar do movimento de institucionalização da Sociologia na escola? Por que debater o ensino de Sociologia a despeito de, em muitos casos, sequer lecionarem no ensino secundário ou na escola normal? Algumas das possíveis motivações são enunciadas nas seções seguintes, cobrindo desde tópicos como a legislação educacional, as expectativas sobre a modernização do Brasil e os esforços em torno da consolidação da Sociologia como ciência e profissão, até os dilemas advindos da docência e do frágil repertório dos estudantes que ingressavam no ensino superior sem uma base sólida de conhecimentos de Ciências Humanas.

\footnotetext{
2 Este trabalho é derivado da tese de doutoramento de Neuhold (2014), desenvolvida no âmbito do Programa de Pós-Graduação em Educação da Universidade de São Paulo, intitulada Sociologia do ensino de Sociologia: os debates acadêmicos sobre a constituição de uma disciplina escolar. Versão preliminar de uma seção deste texto foi apresentada ao Grupo de Trabalho Ensino de Sociologia, em 2011, no $15^{\circ}$ Congresso Brasileiro de Sociologia.
} 


\section{Um panorama}

No $1^{\circ}$ Congresso Brasileiro de Sociologia, Florestan Fernandes iniciou sua exposição afirmando que "[...] saber se a Sociologia deve ou não ser ensinada no curso secundário se coloca entre os temas de maior responsabilidade com que precisam se defrontar os sociólogos do Brasil" (FERNANDES, 1955, p. 89). Era junho de 1954 e aquele que se tornaria o "perfil acabado de intelectual acadêmico" (NOVAIS; ARRUDA, 1998, p. 8), já professor da Universidade de São Paulo, sugeria que o ensino de Sociologia no meio escolar se tornasse objeto de reflexão a partir do próprio instrumental teórico das Ciências Sociais.

Florestan Fernandes não foi o único expoente da academia a tomar parte nos debates sobre a Sociologia enquanto disciplina escolar. Em 1927, Delgado de Carvalho, autor de pelo menos cinco livros didáticos de Sociologia (MEUCCI, 2011), lecionou essa disciplina no Colégio Pedro II e na Escola Normal do Distrito Federal, no Rio de Janeiro (SOARES, 2009). Já o educador Antônio Carneiro Leão, professor da Universidade do Brasil, criou a cadeira de Sociologia na Escola Normal de Pernambuco, que teve como titular, entre 1929 e 1930, Gilberto Freyre (MEUCCI, 2005, 2007). Por sua vez, Fernando de Azevedo, um dos signatários do Manifesto dos Pioneiros da Educação Nova, introduziu a Sociologia no currículo da Escola Normal do Rio de Janeiro em 1928 (quando conduziu a reforma da instrução pública do Distrito Federal) e foi professor catedrático de Sociologia da Escola Normal de São Paulo em 1931, antes de ingressar na Universidade de São Paulo, onde respondeu pela cadeira de Sociologia Educacional (a partir de 1934) e de Sociologia II (depois de 1942) (SAVIANI, 2010; INSTITUTO DE ESTUDOS BRASILEIROS, 2000). Os professores Roger Bastide, da Universidade de São Paulo, e Donald Pierson, da Escola de Sociologia e Política, estiveram envolvidos com o Instituto de Educação de Florianópolis, quando a Sociologia foi elevada a disciplina do curso normal de formação de professores para o ensino primário (SANTOS, 2004). Emilio Willems, professor da Escola de Sociologia e Política e da Universidade de São Paulo, lecionou no ensino secundário e em escolas normais, em Santa Catarina e em São Paulo, ao longo de uma década, antes de se estabelecer no ensino superior (NEUHOLD, 2014).

Esses e outros intelectuais também responderam pela autoria de inúmeros manuais didáticos e demais obras de difusão dos conhecimentos sociológicos. Simone Meucci (2011) listou 35 títulos lançados entre 1900 e 1945 no Brasil, sendo que, desses, apenas cinco datam de anos anteriores a 1930. Entre seus autores, encontravam-se muitos daqueles intelectuais que lecionaram no ensino secundário e superior, além de figuras com trajetória direcionada exclusivamente ao magistério no ensino secundário e escolas normais, que pouca ou nenhuma atuação tiveram na academia ou nas associações científicas de Sociologia (MEUCCI, 2011). Segundo Meucci $(2011$, p. 23), "[...] o sucesso editorial dessas obras coloca seus autores entre os mais notáveis divulgadores da Sociologia no sistema escolar e acadêmico brasileiro".

Aos manuais didáticos somavam-se dicionários, periódicos especializados, traduções e coletâneas de textos que também ajudaram a constituir o acervo que subsidiou o ensino e a pesquisa em Ciências Sociais. Emilio Willems organizou o Dicionário de Etnologia e Sociologia (1939), ao lado de Herbert Baldus, o Dicionário de Sociologia (1950), a coletânea de textos sociológicos em Leituras Sociológicas (1940) e a revista Sociologia (a partir de 1939), sendo esses dois últimos empreendimentos em parceria com o professor secundarista Antenor Romano Barreto. Por seu turno, Donald Pierson, a convite da Livraria Martins, de São Paulo, e com o apoio da Fundação Rockefeller, dos Estados Unidos, dirigiu um projeto que resultou na tradução de 12 livros publicados entre 1943 e 1949 na chamada Biblioteca de Ciências Sociais (PIERSON, 1987).

Àquelas produções acrescentam-se cerca de 50 textos publicados em periódicos, livros, 
simpósios e anais de congressos, entre artigos, planos de aula, comunicações e uma tese de livre docência, de autoria de professores do ensino superior e secundário (NEUHOLD, 2014). Aqui cabe um destaque para a revista Sociologia, "[...] primeira e por muito tempo única publicação especializada no ramo" (CANDIDO, 2006, p. 287), originalmente criada como uma publicação didática destinada a docentes e alunos das escolas normais, do ensino secundário e superior (NEUHOLD, 2020). Dos 50 textos anteriormente citados, 40 foram veiculados na revista entre os anos de 1939 e 1955 (NEUHOLD, 2014). Ainda que conhecido por sua vinculação à Escola de Sociologia e Política e por seu caráter de difusor da produção científica das Ciências Sociais, o periódico nasceu da iniciativa de dois professores do ensino secundário - Antenor Romano Barreto e Emilio Willems - empenhados em criar "[...] um centro de convergência das atividades escolares no que diz respeito à Sociologia, razão por que destinará parte de suas páginas às publicações de trabalhos dos estudantes da matéria" (SOCIOLOGIA, 1939, p. 6).

Esse panorama inicial ilustra como a presença da Sociologia no ensino secundário também se tornou estratégica no processo de consolidação de um quadro intelectual e institucional das Ciências Sociais no país. Não seria, portanto, exagerado sugerir que "[...] foi pela dimensão do ensino que, inicialmente e oficialmente, a Sociologia instalou-se no Brasil" (SILVA, 2010, p. 16). Nos próximos tópicos, serão pontuadas algumas das motivações que podem ter mobilizado aqueles intelectuais no processo de institucionalização da Sociologia na escola e, mais especificamente, na reflexão sobre o ensino das Ciências Sociais.

\section{Por que debater o ensino de Sociologia?}

Alguns aspectos poderiam ser sublinhados na reflexão sobre as motivações de cientistas sociais e educadores sobre o ensino das Ciências Sociais ter sido pautado nos circuitos especializados do conhecimento. A legislação educacional que alçou a Sociologia à disciplina escolar na década de 1930, demandando todo um suporte didático-pedagógico, apresenta-se como um deles. À condição legal acrescem-se as intersecções projetadas entre as Ciências Sociais e a modernização do país, a expectativa de consolidar a Sociologia como ciência e profissão e a própria criação de saídas profissionais para os egressos dos recém-formados cursos de Ciências Sociais. Tais aspectos serão discutidos nesta seção, tendo como horizonte uma última motivação que recebeu pouco investimento por parte dos estudiosos do pensamento social brasileiro e que diz respeito particularmente à experiência docente.

Primeiramente, caberia mencionar a Reforma Francisco Campos ${ }^{3}$, a qual deu projeção nacional ao ensino de Sociologia na primeira legislação educacional do ensino secundário, válida para todo o território brasileiro. A partir do Decreto $\mathrm{n}^{\circ}$ 19.890/1931, o ensino secundário foi dividido em dois ciclos: o fundamental (com duração de cinco anos e caráter de formação geral) e o complementar (com dois anos e voltado para a formação propedêutica). O ciclo complementar subdividia-se em três modalidades direcionadas aos candidatos dos cursos jurídicos, de Medicina, Farmácia e Odontologia, e de Engenharia e Arquitetura. Nas três modalidades, a Sociologia constava como disciplina da segunda série, estando presente também nas provas finais que equivaliam a um exame de habilitação aos institutos do ensino superior. Em alguns estados, o curso complementar ou os dois anos finais do ensino secundário foram

\footnotetext{
${ }^{3}$ A Reforma Francisco Campos é um conjunto de sete decretos que versou sobre a criação do Conselho Nacional de Educação (Decreto n ${ }^{\circ}$ 19.850/1931), a organização do ensino superior (Decretos no 19.851/1931 e 19.852/1931), a organização do ensino secundário (Decretos $n^{\circ} 19.890 / 1931$ e 21.241/1932) e comercial (Decreto $n^{\circ}$ 20.158/1931), e o reestabelecimento do ensino religioso nas escolas (Decreto $\mathrm{n}^{\circ}$ 19.941/1931) (SAVIANI, 2010). No caso do ensino de Sociologia, interessam principalmente os decretos referentes ao ensino secundário.
} 
denominados "colégio universitário". Ligado diretamente às universidades, dividia-se em seções que respeitavam aquelas já designadas na Reforma Francisco Campos. No Rio de Janeiro, o colégio universitário funcionava anexo à Universidade do Brasil, desde pelo menos 1937 (MORAES, 2007). Em São Paulo, foi criado em 1934, por meio do Decreto no 6.430, como anexo a faculdades da Universidade de São Paulo. Em Minas Gerais, também se atrelava a faculdades do ensino superior (BESSA, 1955).

Para autores da época, a Reforma Francisco Campos, ao tornar obrigatório o estudo da Sociologia no ensino secundário, conferia-lhe "[...] o papel fundamental de uma nova atitude diante da vida, base de um novo humanismo, elemento essencial da integração do homem moderno na sociedade moderna" (COSTA PINTO; CARNEIRO, 1955, p. 18). O próprio texto da reforma traduzia reivindicações presentes no Manifesto dos Pioneiros da Educação Nova. A "tomada de consciência" sobre a importância dos estudos sociológicos correspondia, segundo Costa Pinto e Carneiro (1955, p. 19), a "[...] uma resposta da inteligência nacional ao desafio representado pelos problemas colocados diante dela pelas mudanças sociais em processo, problemas que o movimento revolucionário que inaugurou o decênio tinha que, como tarefa histórica, atacar de frente" 4 .

A Reforma Francisco Campos e a obrigatoriedade do ensino de Sociologia no curso complementar do ensino secundário, além da já estabelecida inclusão da disciplina nas escolas normais a partir de 1928, seriam a resposta mais óbvia para um possível interesse dos intelectuais pela Sociologia enquanto disciplina escolar. Todavia, é sabido que a questão continuou sendo discutida entre as décadas de 1940 e 1950, mesmo depois de decretada a Lei Orgânica do Ensino Secundário (Decreto-Lei no $\left.{ }^{\circ} .244 / 1942\right)^{5}$ que, entre outros aspectos, retirou a Sociologia do rol de disciplinas do ensino secundário. Naquela mesma década em que a Sociologia perdia seu curto estatuto de disciplina escolar, a revista Sociologia (1949) reuniu artigos sobre a temática sob o título "Symposium sobre o Ensino de Sociologia e Etnologia" e, seis anos mais tarde, o assunto tornou-se pauta de debates acalorados no $1^{\circ}$ Congresso Brasileiro de Sociologia (1955) (NEUHOLD, 2017).

Em outros termos, é verdade que a qualidade de disciplina escolar, estabelecida na forma de lei, atribuiu (e continua atribuindo) um status "especial" à Sociologia, podendo tornar urgente a mobilização de intelectuais para qualificar o seu ensino, selecionar conteúdos e métodos, definir objetivos e estratégias didáticas. É verdade também que tanto o Symposium sobre o Ensino de Sociologia e Etnologia quanto o $1^{\circ}$ Congresso Brasileiro de Sociologia foram contemporâneos à elaboração dos anteprojetos da primeira Lei de Diretrizes e Bases da Educação Nacional, o que poderia ter acendido as expectativas dos cientistas sociais de reconquistarem um lugar para a Sociologia na escola. Contudo, a formalização da disciplina na legislação educacional não foi, historicamente, condição suficiente para justificar ou estimular o interesse desses mesmos intelectuais pelas especificidades do seu ensino na escola nem mesmo para garantir o acesso de professores da educação básica aos fóruns especializados das Ciências Sociais (MORAES, 2003). O estatuto legal da Sociologia no currículo escolar,

\footnotetext{
4 Esses mesmos autores, contudo, concluiriam que a reforma não rendeu os frutos prometidos (PINTO; CARNEIRO, 1955). Os programas de Sociologia foram entregues a pessoas alheias aos debates das Ciências Sociais e o próprio Francisco Campos mostrou-se como uma figura com posições contraditórias. Ao mesmo tempo em que tentou implementar uma política educacional de caráter nacional e ratificou a permanência da Sociologia no ensino secundário, em uma reforma revestida de caráter modernizante e democrático, Campos estabeleceu o ensino religioso nas escolas públicas (Decreto no 19.941/1931) e redigiu a Constituição Federal que instituiu o Estado Novo (SAVIANI, 2010).

5 Esse e outros decretos-lei do período que reorganizaram o sistema educacional ficaram conhecidos como "Reforma Capanema".
} 
conforme argumenta Amaury César Moraes (2003, p. 9), “[...] pouco diz em termos mais profundos das experiências desse ensino, ou dos debates a seu favor ou contra". Cabe lembrar que a Sociologia voltou a compor o currículo de parte das escolas brasileiras em meados do decênio de 1980, mas a primeira investigação sobre o assunto, no âmbito de programas de pósgraduação, só foi defendida em 1993 por Lesi Correa. No mais, a pesquisa sobre a temática ganharia volume apenas nas duas primeiras décadas do século XXI (HANDFAS; POLESSA, 2014; NEUHOLD, 2014; OLIVEIRA, 2015), sobretudo a partir das mobilizações para a aprovação da Lei $\mathrm{n}^{\circ} 11.684 / 2008$, que tornaria obrigatório o ensino de Sociologia em todos os estabelecimentos de ensino médio.

A intersecção entre a Sociologia como ciência, a modernização do país e a democratização da sociedade (SARANDY, 2007; MEUCCI, 2011) poderia ser sublinhada como um segundo aspecto para entender o interesse suscitado pelo ensino de Sociologia entre a intelectualidade das décadas de 1930 a 1950. De fato, a Sociologia compôs a promessa de formar indivíduos com uma postura racional e democrática diante dos acontecimentos sociais, sendo muitas vezes vista, no sentido atribuído por Mannheim, como técnica social que modelaria as relações sociais (CANDIDO, 1949). Essa perspectiva perdurou mesmo diante da ambiguidade de contextos daquela época, quando o autoritarismo do Estado Novo conviveu com uma perspectiva liberal no âmbito escolar (MORAES, 2003). Entre os cientistas sociais, Luiz de Aguiar Costa Pinto entendia que a disciplina propiciava noções básicas e gerais ao aluno, libertando-o de uma visão estática e dramática do mundo e fornecendo-lhe técnicas para que assumisse uma "posição objetiva diante dos fenômenos sociais" (COSTA PINTO, 1949, p. 93). Para Florestan Fernandes (1955, p. 98), a educação pelas Ciências Sociais criava "[...] personalidades mais aptas à participação nas atividades políticas, como estas se processam no Estado moderno".

Um terceiro aspecto a ser considerado diz respeito à formação de um pensamento sociológico brasileiro, o que envolvia também o ensino das Ciências Sociais (SILVA et al., 2002). Costa Pinto (1944, p. 15) entendia que "[...] os que se interessam pelo estudo de qualquer ciência hão de se interessar, também, diretamente, por seu ensino que é, em suma, o modo pelo qual ela pode subsistir de modo útil, desenvolvendo-se e exercendo sua plena função cultural”. Pierson apontava que o ensino secundário e o ensino superior constituíam uma das alternativas para difundir os conhecimentos de uma ciência, assim como os livros, conferências, conversas, artigos em periódicos especializados e, dizia ele, "de vez em quando, nas [revistas] populares" (PIERSON, 1949, p. 317). Fernando de Azevedo (1955), ao propor uma leitura sobre a história da Sociologia no Brasil, destacou o impacto da introdução dessa disciplina no ensino superior e secundário sobre o teor da produção sociológica.

Com a mesma pretensão de recriar uma história da Sociologia, Antonio Candido, em artigo de 1959, publicado originalmente na Enciclopédia Delta-Larousse, sugeria que a constituição da Sociologia como "ciência e profissão, diferenciada de outras disciplinas afins" (CANDIDO, 2006, p. 289) só tomou forma, de fato, depois de 1940. Esse processo envolveu a organização do trabalho sociológico, o "novo espírito" que o presidia (distante da mentalidade literária e com certo sincretismo e indiferenciação em relação a outras disciplinas) e as obras publicadas (CANDIDO, 2006). Porém, desde a década de 1930, “[...] o fato mais importante para a formação da Sociologia" (CANDIDO, 2006, p. 284) teria sido, nada mais nada menos, do que o seu estabelecimento no ensino. Os educadores, por seu turno, confluíam suas demandas " [...] para a formação profissional do professor primário e para a elaboração de uma teoria educacional adequada, sentindo logo a seguir a necessidade de estabelecer o seu ensino em nível superior" (CANDIDO, 2006, p. 284).

Vale pontuar um quarto aspecto tido muitas vezes como uma hipótese fraca, se 

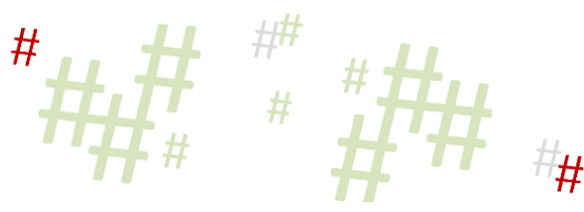

considerada isoladamente (FERNANDES, 1955; VILLAS-BÔAS, 1998), mas que não merece ser ignorado: a absorção dos sociólogos no magistério. Antonio Candido (1949), por exemplo, definia o escopo da Sociologia entre a formação de pesquisadores, a formação de professores e a iniciação nos conhecimentos sociológicos entre alunos não especializados. Costa Pinto (1944, p. 19) também vislumbrava três saídas profissionais para os egressos dos cursos de Ciências Sociais, abarcando a formação de técnicos para os vários setores das Ciências Sociais; de estudiosos "da vida humana e associativa e dos problemas sociais e econômicos do Brasil"; e de professores, antes de 1942, basicamente do ensino secundário. Esse último campo de atuação profissional ganhava destaque, muito embora tivesse sido desmontado uma década depois de estabelecido pela Reforma Francisco Campos. E completava: em um meio no qual "[...] o mercado de trabalho para mão de obra tão especializada é necessariamente restrito [...] não fazia sentido que um curso universitário existisse, como esforço isolado, exclusivamente para formar técnicos e pesquisadores de alto nível em Ciências Sociais" (COSTA PINTO; CARNEIRO, 1955, p. 31).

Com efeito, a obrigatoriedade do ensino de Sociologia no nível secundário e nas escolas normais ampliava o campo de atuação profissional de sociólogos em uma área que gozava, à época, de algum prestígio e estabilidade. É verdade que Heloísa Pontes, comentando as perspectivas profissionais que poderiam ter motivado Florestan Fernandes a ingressar no curso de Ciências Sociais, sugeriu que a profissão estava quase ausente da escolha do intelectual, pois na década de 1940, "[...] ninguém sabia ao certo o que era ser cientista social e muito menos o que se poderia esperar desse tipo de profissão" (PONTES, 1996, p. 172). Ainda assim, o mesmo Florestan Fernandes assumiu, em 1945, a vaga de assistente de Fernando de Azevedo na cadeira de Sociologia II da Universidade de São Paulo porque o colega José Francisco de Camargo deixara o posto para concorrer a uma cadeira de Sociologia na escola normal. Como relatou Antonio Candido (2010, p. 348-349), o cargo na escola normal "[...] naquele tempo era não apenas melhor remunerado [do que o do ensino superior], mas tinha a vantagem de dar acesso a uma carreira, com aposentadoria assegurada". Sobre o cargo de assistente, Candido (2010, p. 348-349) esclarecia que se tratava de um funcionário sem qualquer garantia, sendo "[...] nomeado por indicação de um professor e demissível a qualquer momento por simples comunicação escrita dele, sem necessidade sequer de justificativa". E continuava: "Por isso, não tínhamos carreira e éramos assistentes dos professores, mais do que da instituição (o que, seja dito, não era ruim se o professor fosse bom)" (CANDIDO, 2010, p. 349).

Emilio Willems, com pouco entusiasmo, também falava sobre sua experiência no ensino secundário, fonte de renda enquanto não conseguiu se estabelecer no ensino superior.

[...] O quinquênio de 1936 a 1941 foi o período mais difícil de minha vida profissional. Estava decidido a prosseguir na carreira de cientista social, mas a responsabilidade de prover às necessidades de minha família forçava-me a continuar no magistério secundário, que achava cada vez menos satisfatório. Já não sei como consegui conciliar as exigências desmedidas do ensino colegial com a preparação do concurso de livredocência que prestei em 1937 em Sociologia Educacional. Ganhei o título, mas a minha situação econômica não melhorou até o ano seguinte, quando fui nomeado assistente. Com a extinção do Instituto de Educação, os cursos de nível superior passaram para a Faculdade de Filosofia, Ciências e Letras da Universidade de São Paulo. Somente em 1941, com a nomeação para a 'disciplina' de Antropologia, estava eu em condições de deixar, por completo, o magistério secundário. Ademais, no mesmo ano, a Escola de Sociologia e Política convidou-me para lecionar Antropologia Social e Sociologia (WILLEMS, 1987, p. 119). 
De origem alemã, Willems ${ }^{6}$ chegou ao Brasil em 1931, aos 26 anos. Já doutor em Filosofia pela Universidade de Berlim, foi professor de um colégio de padres na cidade catarinense de Brusque, onde ensinava latim, grego e francês (WILLEMS, 1987). Ainda em Brusque, colaborou na fundação de uma escola secundária, também ligada à Igreja Católica, onde desempenhou diversas funções didáticas. Em 1934, mudou-se para o norte do Paraná, onde continuou lecionando em um "[...] ginásio recém-fundado por uma congregação religiosa desprovida de experiências pedagógicas" (WILLEMS, 1987, p. 119). Em certa ocasião, conheceu Sampaio Dória, responsável pela reforma da instrução pública em São Paulo na década de 1920, que o convidou para lecionar no Liceu Nacional Rio Branco, uma das "[...] mais reputadas escolas secundárias de São Paulo" (LIMONGI, 2001, p. 179), cidade em que Willems se estabeleceu com a família em meados de 1936. O magistério continuou sendo sua fonte de renda, muito embora não o satisfizesse.

\section{Desafios da docência}

Diferentes motivações podem ter contribuído para que o ensino de Sociologia adentrasse os debates dos circuitos especializados do conhecimento na primeira metade do século XX. Algumas delas foram listadas na seção anterior, mas ainda não abarcam, em profundidade, a dimensão do ensino, tampouco o olhar daqueles cientistas sociais sobre a docência.

O ensino de Sociologia mostrou-se um desafio para os intelectuais, independentemente do nível de ensino no qual estivessem presentes - nas escolas normais, no ensino secundário ou superior -, de sua audiência - universitários, jovens secundaristas ou normalistas - ou de seus objetivos - formar pesquisadores, candidatos ao ensino superior ou ao magistério no ensino primário. Tornava-se ainda mais complexo quando se tratava de ensinar uma ciência que se consolidava nos bancos universitários e que, muitas vezes, não correspondia à formação inicial daqueles que assumiam a sua docência.

Emilio Willems (1987, p. 118) narrava que, quando decidiu permanecer em Brusque para "[...] colaborar com o vigário na fundação de uma escola secundária", desempenhou "“[...] funções didáticas das mais diversas para as quais estava mal preparado”. E continuava:

\footnotetext{
Pouco me adiantavam a licenciatura em Ciências Econômicas e o diploma de doutor em Filosofia, ambos pela Universidade de Berlim. Estava cheio de ideias livrescas, mas faltavam-me método e prática de pesquisa em campo, que as universidades europeias daquele tempo deixavam inteiramente à iniciativa do estudante (WILLEMS, 1987, p. 118).
}

Nesse sentido, convém sublinhar mais um aspecto que poderia estar presente no interesse de alguns intelectuais pelo ensino de Sociologia: as dificuldades advindas do próprio exercício da docência.

Florestan Fernandes e Antonio Candido mais de uma vez admitiram suas angústias com o magistério. O diagnóstico abrangia desde a falta de preparação pedagógica de assistentes e professores (quando ainda eram graduandos), passando pela frágil formação dos estudantes que chegavam à universidade e para os quais davam aulas (já como assistentes), até o desprestígio das Ciências Sociais enquanto disciplina científica e a incipiente produção sociológica

\footnotetext{
${ }^{6}$ Sobre a trajetória acadêmica de Emilio Willems e suas contribuições para as Ciências Sociais brasileiras, ver os artigos de Gláucia Villas-Bôas (2000), João Baptista Borges Pereira (1994), Luís Jackson (2009) e o próprio depoimento do autor em entrevista concedida a Mariza Corrêa (WILLEMS, 1987).
} 
brasileira que impunha outros empecilhos ao ensino da disciplina (vivenciada quando se tornaram professores do ensino superior).

Um episódio de Florestan Fernandes com uma professora assistente da Universidade de São Paulo contribuiu para a reflexão sobre o interesse de alguns cientistas sociais, àquela altura, por questões relacionadas ao ensino de Sociologia. A estreia de Florestan em uma revista científica aconteceu com a publicação, na revista Sociologia, dos desdobramentos de um trabalho $^{7}$ originalmente escrito para uma disciplina ministrada por Roger Bastide na Universidade de São Paulo. Em viagem, Bastide deixou a disciplina sob os cuidados de sua assistente (GARCIA, 2002). "Aspectos do folclore paulistano: resultados de uma pesquisa de campo" era o segundo trabalho que Florestan apresentava à disciplina de Bastide: no primeiro, sobre a crise causal na explicação sociológica, recebeu nota 4,5 (de 10); Bastide disse que esperava uma dissertação, mas recebeu uma reportagem (GARCIA, 2002). No segundo trabalho, a professora assistente deu-lhe 9. Descontente, Florestan buscou explicações e ouviu de Lavínia Villela que havia levado o enfoque sociológico longe demais (GARCIA, 2002). No retorno de Bastide, decidiu mostrar-lhe o texto; o professor disse-lhe que estava no caminho certo e que, quanto à perspectiva analítica, deveria aprofundá-la. Era 1941 e Florestan cursava o primeiro ano de Ciências Sociais. O reconhecimento de Bastide rendeu frutos à carreira do estudante pobre, até então quase invisível no meio de seus colegas poliglotas que "[...] monopolizavam a atenção dos professores estrangeiros" (GARCIA, 2002, p. 83). Florestan Fernandes ganhou projeção, aproximou-se de Bastide (com quem discutiu questões referentes à interpretação sociológica) e, por intermédio dele, de Emilio Willems (que lhe orientou sobre a coleta de dados, abriu portas para que publicasse trabalhos em Sociologia e para que desenvolvesse seus estudos de pós-graduação na Escola de Sociologia e Política) e de Sérgio Milliet (que lhe auxiliaria a publicar n'O Estado de S. Paulo) (PONTES, 1999).

$\mathrm{Na}$ década de 1970, Florestan recuperaria o episódio dos seus primeiros anos da graduação para sugerir que a professora assistente estava "[...] mais perto dos folcloristas que dos sociólogos" (FERNANDES apud GARCIA, 2002, p. 84-85). Quando orientado por Willems sobre como proceder em uma pesquisa de campo, Florestan percebeu que faltava à professora não apenas a preocupação com a coleta de dados, como também o preparo para lecionar: '[...] pela primeira vez vi qual era a diferença entre o 'amador' e o 'profissional', o 'aprendiz' e o 'mestre'; e creio que aproveitei bem a lição, que iria servir de ponto de referência no meu modo de entender e praticar a pesquisa empírica sistemática como sociólogo" (FERNANDES apud GARCIA, 2002, p. 84).

Tivesse a professora lhe dado mais um ponto e a indignação de Florestan não seria tamanha? Afinal, uma nota 9 expressava reconhecimento pelo trabalho de um estudante e o próprio Fernando de Azevedo dizia que um aluno extraordinário mereceria no máximo um $8^{8}$. Provavelmente, o descontentamento adviria da atuação de outros assistentes, até porque

\footnotetext{
7 "Folklore e grupos infantis" (v. 4, n. 4, 1942), "Educação e cultura infantil" (v. 5, n. 2, 1943), "Congadas e batuques em Sorocaba" (v. 5, n. 3, 1943) e "Aspectos mágicos do folclore paulistano" (v. 6, n. 2-3, 1944) foram textos decorrentes do trabalho elaborado originalmente para a disciplina ofertada por Bastide.

8 Ver o depoimento de Florestan Fernandes (GARCIA, 2002) sobre a "rebeldia" dele e de Antonio Candido diante das orientações de Fernando de Azevedo quando eram seus assistentes. Narrou, por exemplo, que sendo responsáveis por avaliar as provas aplicadas por Fernando de Azevedo, Antonio Candido e ele começaram a desconstruir o "[...] tabu que vinha das escolas normais e da mentalidade que prevalecia entre professores a respeito da gradação da inteligência" (FERNANDES apud GARCIA, 2002, p. 136-137). Fernando de Azevedo, contrário à atribuição de nota máxima aos alunos da graduação - dizia-se proveniente "[...] da tradição de uma escola na qual dez era para Deus, nove para os professores e, para alunos excepcionais, a partir de oito" -, aos poucos teve que aceitar os critérios de notas de Florestan Fernandes e Antonio Candido, que atribuíram nota 10, respectivamente, a um texto de Roque Spencer Maciel de Barros - "um trabalho muito bem feito para um estudante", nas palavras de Florestan - e de Maria Isaura Pereira de Queiroz - "trabalho excepcional", segundo Antonio Candido (FERNANDES, 1995, p. 190-192).
} 
Florestan Fernandes e outros colegas concordavam que o ensino que recebiam "[...] tinha certas deficiências e muitas delas provinham da má qualidade intelectual ou do despreparo dos assistentes" (FERNANDES apud GARCIA, 2002, p. 88). Para ele, "[...] alguns seminários, nas mãos de assistentes que negligenciavam o ensino, alcançavam importância medíocre" (FERNANDES, 1975, p. 10). O mesmo Florestan ponderou sobre sua própria maturidade para assumir o cargo de assistente quando concluiu a graduação e recebeu convite de Fernando de Azevedo. Na ocasião, Azevedo foi surpreendido com a resposta: "Dr. Fernando, o senhor tem toda a responsabilidade nesse convite. O senhor está convidando um aluno... eu não sou um professor. O senhor deveria chamar um professor, essa é a sua responsabilidade. Se eu falhar, aí o senhor não pode transferir a culpa para mim" (FERNANDES apud GARCIA, 2002, p. 100). Florestan Fernandes foi tão convincente que, de fato, deixou Fernando de Azevedo em dúvida sobre a escolha. Quem lhe salvou, diria anos depois, foi Antonio Candido, que intercedeu em favor daquele que seria seu colega como assistente de Fernando de Azevedo (GARCIA, 2002).

A suposta falta de preparo dos professores assistentes, todavia, e a própria resposta de Florestan Fernandes a Fernando de Azevedo - " [...] o senhor está convidando um aluno... eu não sou um professor" (FERNANDES apud GARCIA, 2002, p. 100) - ajudam a compreender o lugar da discussão sobre a constituição de uma identidade docente aliada à própria reflexão sobre o ensino de Sociologia. Todavia, não respondem necessariamente por que esses mesmos cientistas sociais tomaram parte nas discussões sobre a Sociologia enquanto disciplina escolar.

Exceção feita a Fernando de Azevedo, a maior preocupação dos cientistas sociais não remetia exatamente ao ensino secundário enquanto etapa de formação, mas antes, aos estudantes que ingressavam no ensino superior. Enquanto docentes desse nível de ensino, muitos intelectuais se deparavam com a dificuldade de lecionar para um público que transitava entre os temas das Ciências Sociais com pouca desenvoltura. E qual seria a causa de tamanha dificuldade? Uma das respostas possíveis remetia à formação recebida no ensino secundário.

O próprio Florestan Fernandes (2006), em depoimento de 1978, descrevia sua insegurança ao concluir o curso de Ciências Sociais na Faculdade de Filosofia, Ciências e Letras da Universidade de São Paulo. Dizia ter sido acometido por uma crise que não era psicológica, mas moral. Mesmo depois de graduado, ainda se perguntava o que era a Sociologia e as Ciências Sociais e se sabia o suficiente para se tornar um sociólogo. Convencido de que ainda havia muito a aprender, elaborou um programa de leituras intensivas, que chegava a ocupar 18 horas de seus dias. Esse autodidatismo fora necessário porque, nas palavras do autor, "[...] nós não tínhamos um ensino secundário que alimentasse o desenvolvimento intelectual do estudante" (FERNANDES, 2006, p. 14). O jovem que chegava à Universidade de São Paulo - entre os quais o próprio Florestan - "[...] era um estudante com deficiências muito graves [...]" que encontrava "[...] condições precárias para montar sua vida intelectual" (FERNANDES, 2006, p. 19).

Florestan Fernandes (2006, p. 14) explicava que na Faculdade de Filosofia havia um preconceito muito grande contra um "ensino de tipo elementar". Desde o primeiro ano, liamse livros originais, com forte ênfase no aspecto teórico. Em termos práticos, o estudante que não havia sido preparado no ensino secundário para lidar com essa literatura deparava-se com um ensino fortemente abstrato (FERNANDES, 2006). Resultado: os cursos que começavam o ano com 50 ou 60 alunos, chegavam ao segundo semestre com 25: "Eles [alunos] fugiam do

\footnotetext{
${ }^{9}$ Florestan Fernandes narrava que, junto com seus colegas, chegou a fazer uma "conspiração" para sabatinar os assistentes e colocar seus conhecimentos a prova: "Aqueles assistentes ficaram sob o fogo cruzado de debates infindáveis; alguém dentre nós se encarregava, organizadamente, do municiamento crítico em determinada disciplina” (GARCIA, 2002, p. 88).
} 
curso, ou seja, de mim! Fugiam porque não tinham como acompanhar aquele curso", desabafava Fernandes (2006, p. 19). Se essa era uma regra aceitável para o meio intelectual brasileiro, para Florestan Fernandes precisava ser criticada, de forma impessoal e institucional, e repensada.

Junto com Antonio Candido - "[...] companheiro mais chegado que eu tinha, pouco mais velho que eu e que [...] estava enfrentando reflexões análogas" (FERNANDES, 2006, p. 20) -, Florestan Fernandes simplificou os programas de ensino de Sociologia na Universidade de São Paulo, tornando-os menos gerais e inserindo assuntos que os estudantes não haviam aprendido no ensino secundário. Tratava-se de uma tentativa de superar lacunas que eram do sistema escolar, já que o "[...] estudante vinha com uma bagagem cultural muito pobre” (FERNANDES, 2006, p. 20). Florestan Fernandes (2006) ponderava que, a longo prazo, passou a preocupar-se não apenas com a sua atuação como sociólogo, mas sobretudo com o papel da universidade na formação de intelectuais que poderiam ser professores, investigadores ou técnicos.

Foi assim que, em certa medida, por influência de Florestan Fernandes e de Antonio Candido, os departamentos de Sociologia e de Antropologia da Universidade de São Paulo deram relativa atenção a um ensino mais básico, que orientasse os alunos no que também era mais elementar nas Ciências Sociais (FERNANDES, 2006). Aí também poderia estar assentada a preocupação dos autores e de outros cientistas sociais com a formação dos estudantes do ensino secundário que mais tarde se tornariam alunos do ensino superior sem preparo para lidar com as teorias e métodos das Ciências Sociais.

\section{Considerações finais}

Entre o final da década de 1930 e meados de 1950, alguns intelectuais se pronunciaram sobre o ensino de Sociologia nas escolas brasileiras. Eram, predominantemente, professores do ensino superior e, em menor número, mas com presença significativa, docentes de escolas normais e do ensino secundário paulista. Quais fatores motivaram a participação desses autores no debate sobre o ensino de Sociologia, considerando que muitos deles sequer lecionavam no ensino secundário ou nas escolas normais? Por que debater o ensino de Sociologia nos circuitos especializados do conhecimento?

Alguns aspectos foram salientados neste trabalho, mais na forma de hipóteses do que propriamente de respostas, para contribuir com a reflexão sobre essas indagações. Parte deles já foi explorada em estudos anteriores: a obrigatoriedade da disciplina inscrita na legislação educacional, ainda que por apenas uma década (MACHADO, 1987); a expectativa de modernizar e democratizar o país, contando com a contribuição da Sociologia enquanto ciência que forneceria critérios racionais para a renovação intelectual e política (MEUCCI, 2011); a ambição de institucionalizar a Sociologia no ensino superior, procurando também na escola uma via de legitimação de seus conhecimentos (SILVA et al., 2002) e uma saída profissional. Outros aspectos, menos ambiciosos, não mereceram tanta atenção e são abordados neste trabalho, ainda que na forma de hipótese. Envolvem, por exemplo, a reflexão sobre o lugar do ensino no movimento de consolidação da Sociologia como ciência e profissão, passando pelas dificuldades e angústias oriundas do exercício da docência por parte daqueles intelectuais que se viam diante do desafio de lecionar uma "ciência nova", sem tradição de ensino nas escolas e universidades brasileiras, até as preocupações com o público egresso do ensino secundário que, ao chegar na universidade, transitava com dificuldade entre as teorias e conceitos das Ciências Sociais. 
Convém destacar que as biografias e depoimentos que permitiram estabelecer um fio condutor para as reflexões apresentadas neste artigo acentuaram a preocupação de alguns intelectuais com a legitimação dos conhecimentos sociológicos, a didática da disciplina e a constituição de um campo de atuação profissional que incluía a docência no ensino superior, no ensino secundário e nos cursos de formação de professores. Os textos analisados evidenciaram as próprias dificuldades, encontradas por esses mesmos intelectuais, no exercício da docência e o seu consequente interesse por métodos de difusão dos conhecimentos sociológicos. A essas preocupações somou-se a urgência de repensar o ensino secundário e normal, níveis nos quais o estudante se formava sem ter acesso a saberes considerados indispensáveis para o prosseguimento dos estudos no ensino superior.

É necessário lembrar que essas possíveis respostas à indagação "Por que debater o ensino de Sociologia nos circuitos especializados do conhecimento?" não são excludentes entre si. Antes, reúnem uma teia de fatores que podem ter contribuído para o acolhimento da temática em espaços de produção e difusão do conhecimento em determinados contextos educacionais e intelectuais. Por fim, a despeito dos textos que circularam em periódicos especializados e em eventos científicos, cabe relativizar o interesse dos intelectuais pelo ensino de Sociologia. Isso porque, embora tenha estado presente nos discursos do circuito especializado das Ciências Sociais, extrapolando o ambiente escolar, a temática não chegou a integrar uma agenda de pesquisa. Exceção feita à tese de livre docência de Luiz de Aguiar Costa Pinto (1947), os demais trabalhos desempenharam um papel, de certa forma, político e militante, de demarcar posições no debate e legitimar ou criar um papel social para os cientistas sociais. Não compuseram, propriamente, um projeto investigativo autônomo no interior das Ciências Sociais, muito embora não lhes faltasse fundamentação teórica e um explícito diálogo com a literatura sociológica. Por isso, já no início deste artigo, falava-se em uma narrativa histórica costurada a partir de "ausências" ou, nas palavras de Cardoso (2000, p. 7), de "[...] esquecimentos na história" com potencial, quem sabe, de constituir "cenas organizadoras". O que não se pode esquecer é que essas mesmas ausências do passado, décadas mais tarde, seriam convertidas justamente em "objetos pensáveis", que orientariam a agenda de pesquisa do presente (HANDFAS; POLESSA, 2014; NEUHOLD, 2014; OLIVEIRA, 2015) sobre o ensino de Sociologia.

\section{Referências}

AZEVEDO, Fernando. A Antropologia e a Sociologia no Brasil. In: As ciências no Brasil. v. 2. São Paulo: Melhoramentos, 1955, p. 353-399.

BESSA, Pedro Parafita de. O estudo das Ciências Sociais em Minas Gerais. In: CONGRESSO BRASILEIRO DE SOCIOLOGIA, 1., 1955, São Paulo. Anais... São Paulo, 1955, p. 299-304.

BOURDIEU, Pierre. Entrevista com Pierre Bourdieu: depoimento. Teoria e Educação, Porto Alegre, Pannonica, v. 3, p. 3-8, 1991. Entrevista concedida a Menga Ludke.

BOURDIEU, Pierre. Método científico e hierarquia social dos objetos. In: NOGUEIRA, Maria Alice; CATANI, Afrânio (org.). Escritos de Educação. 11. ed. Rio de Janeiro: Vozes, 2010, p. 33-38.

BRASIL. Decreto n. 16.782 A, de 13 de janeiro de 1925. Estabelece o concurso da união para a difusão do ensino primário, organiza o Departamento Nacional de Ensino, reforma o ensino secundário e superior e dá outras providencias. Rio de Janeiro, 1925. 
BRASIL. Decreto n. 19.890, de 18 de abril de 1931. Dispõe sobre a organização do ensino secundário. Rio de Janeiro, 1932.

BRASIL. Decreto n. 2.940, de 22 de novembro de 1928. Regulamenta o ensino. Rio de Janeiro, 1929.

BRASIL. Decreto n. 21.241, de 4 de abril de 1932. Consolida as disposições sobre a organização do ensino secundário e dá outras providências. Rio de Janeiro, 1932.

BRASIL. Decreto n. 6.130, de 1 de março de 1876. Altera os regulamentos do imperial Colégio de Pedro II. Rio de Janeiro, 1876.

BRASIL. Decreto n. 7.247, de 19 de abril de 1879. Reforma o ensino primário e secundário no município da corte e o superior em todo o Império. Rio de Janeiro, 1879.

BRASIL. Decreto n. 981, de 8 de novembro de 1890. Aprova o regulamento da instrução primária e secundária do Distrito Federal. Rio de Janeiro, 1890.

BRASIL. Decreto-lei n. 4.244, de 9 de abril de 1942. Lei orgânica do ensino secundário. Rio de Janeiro, 1942.

CANDIDO, Antonio. A Sociologia no Brasil. Tempo Social, São Paulo, v. 18, n. 1, p. 271 301, jun. 2006.

CANDIDO, Antonio. O jovem Florestan Fernandes. In: FERNANDES, Florestan. Florestan Fernandes: leituras e legados. São Paulo: Global, 2010, p. 347-352.

CANDIDO, Antonio. O significado de Raízes do Brasil. In: HOLANDA, Sérgio Buarque.

Raízes do Brasil. 13. ed. Rio de Janeiro: José Olympo, 1979, p. XI-XXII.

CANDIDO, Antonio. Sociologia: ensino e estudo. Sociologia, São Paulo, v. 11, n. 3, 1949.

(Symposium sobre o Ensino de Sociologia e Etnologia).

CARDOSO, Irene. Narrativa e história. Tempo Social, São Paulo, v. 12, n. 2, p. 313, nov. 2000.

CONGRESSO BRASILEIRO DE SOCIOLOGIA, 1., 1954, São Paulo. Anais... São Paulo, 1955.

CORREA, Lesi. A importância da disciplina Sociologia no currículo de 20 grau: a questão da cidadania, problemas inerentes ao estudo da disciplina em 2 escolas oficiais de 20 grau de Londrina. 1993. Dissertação (Mestrado em Educação) - Faculdade de Educação, Pontifícia Universidade Católica de São Paulo, São Paulo, 1993.

COSTA PINTO, Luiz de Aguiar Costa. Ensino da Sociologia nas escolas normais.

Sociologia, São Paulo, v. 11, n. 3, 1949. (Symposium sobre o Ensino de Sociologia e Etnologia).

COSTA PINTO, Luiz de Aguiar Costa. O ensino da Sociologia na escola secundária. 1947. Tese (Livre docência em Sociologia) - Faculdade Nacional de Filosofia, Universidade do Brasil, Rio de Janeiro, 1947.

COSTA PINTO, Luiz de Aguiar Costa. O ensino das Ciências Sociais no Brasil. Sociologia, São Paulo, v. 6, n. 1, 1944.

COSTA PINTO, Luiz de Aguiar; CARNEIRO, Edison. As Ciências Sociais no Brasil. Rio de Janeiro: Capes, 1955. (Série Estudos e Ensaios - 6). 
CUNHA, Luiz Antônio. Educação e classes sociais no manifesto de 32: perguntas sem respostas. Revista da Faculdade de Educação, São Paulo, v. 20, n. 1-2, p. 132-150, 1994. FERNANDES, Florestan. A contestação necessária. São Paulo: Ática, 1995.

FERNANDES, Florestan. Florestan Fernandes. In: BASTOS, Elide Rugai et al. Conversas com sociólogos brasileiros. São Paulo: Editora 34, 2006, p. 13-48.

FERNANDES, Florestan. O ensino da Sociologia na escola secundária brasileira. In: CONGRESSO BRASILEIRO DE SOCIOLOGIA, 1., 1954, São Paulo. Anais... São Paulo: USP, 1955, p. 89-106.

FERNANDES, Florestan. Sobre o trabalho teórico. Trans/Form/Ação, Marília, v. 2, p. 5-86, 1975.

GARCIA, Sylvia Gemignani. Destino ímpar: sobre a formação de Florestan Fernandes. São Paulo: Editora 34, 2002.

HANDFAS, Anita; POLESSA, Julia. O estado da arte da produção científica sobre o ensino de sociologia na educação básica. BIB, Revista Brasileira de Informação Bibliográfica em Ciências Sociais, v. 1, p. 45-61, 2014.

IANNI, Octavio. Pensamento social no Brasil. Bauru: Edusc, 2004.

INSTITUTO DE ESTUDOS BRASILEIROS. Arquivo Fernando de Azevedo. São Paulo: Universidade de São Paulo, 2000.

LIMONGI, Fernando. Mentores e clientelas da Universidade de São Paulo. In: MICELI, Sérgio (org.). História das Ciências Sociais. São Paulo: Sumaré, 2001, p. 135-221.

MACHADO, Celso de Souza. O ensino da Sociologia na escola secundária brasileira: levantamento preliminar. Revista da Faculdade de Educação, São Paulo, v. 13, n. 1, 1987, p. $115-142$.

MANIFESTOS dos pioneiros da Educação Nova (1932) e dos educadores 1959 Fernando de Azevedo... [et al.]. Recife: Fundação Joaquim Nabuco, Editora Massangana, 2010.

MEUCCI, Simone. A experiência docente de Gilberto Freyre na Escola Normal de Pernambuco (1929-1930). Caderno CRH, Salvador, v. 18, n. 44, p. 207-214, maio/ago. 2005.

MEUCCI, Simone. Entre a escola nova e a oligarquia: a institucionalização da Sociologia na Escola Normal de Pernambuco - 1929-1930. Cronos, Natal, v. 8, n. 2, p. 451-474, jul./dez. 2007.

MEUCCI, Simone. Gilberto Freyre e a Sociologia no Brasil: da sistematização à constituição do campo científico. 2006. Tese (Doutorado em Sociologia) - Instituto de Filosofia e Ciências Humanas, Universidade Estadual de Campinas, Campinas, 2006.

MEUCCI, Simone. Institucionalização da Sociologia no Brasil: os primeiros manuais e cursos. 2000. Dissertação (Mestrado em Sociologia) - Instituto de Filosofia e Ciências Humanas, Universidade Estadual de Campinas, Campinas, 2000.

MEUCCI, Simone. Institucionalização da Sociologia no Brasil: primeiros manuais e cursos. São Paulo: Hucitec; Fapesp, 2011.

MORAES, Amaury Cesar. Licenciatura em Ciências Sociais e ensino de Sociologia: entre o balanço e o relato. Tempo Social, São Paulo, USP, v. 15, n. 1, p. 5-20, 2003. 
MORAES, Tatiana Beaklini. O Colégio Universitário da Universidade do Brasil: 1937 a 1942. In: SEMINÁRIO MEMÓRIA, DOCUMENTAÇÃO E PESQUISA: UNIVERSIDADE E OS MÚLTIPLOS OLHARES DE SI MESMA, 2007, Rio de Janeiro. Trabalhos apresentados no... Rio de Janeiro: UFRJ, Fórum de Ciência e Cultura, Sistema de Bibliotecas e Informação, 2007, p. 162-178.

NEUHOLD, Roberta dos Reis. A Sociologia como disciplina escolar em debate no $1^{\circ}$ Congresso Brasileiro de Sociologia. Cadernos da Associação Brasileira de Ensino de Ciências Sociais, v. 1, n. 2, p. 5-26, jul./dez. 2017.

NEUHOLD, Roberta dos Reis. Contribuições do meio acadêmico-científico aos debates sobre o ensino de Sociologia na escola básica. In: CONGRESSO BRASILEIRO DE SOCIOLOGIA, 1., 2011, Curitiba. Anais... Curitiba, 2011.

NEUHOLD, Roberta dos Reis. O ensino de Sociologia e a Revista Sociologia: didática e científica. In: BRUNETTA, Antonio Alberto; BODART, Cristiano das Neves; CIGALES, Marcelo Pinheiro. Dicionário do Ensino de Sociologia. Maceió: Editora Café com Sociologia, 2020, p. 361-365.

NEUHOLD, Roberta dos Reis. Sociologia do ensino de Sociologia: os debates acadêmicos sobre a constituição de uma disciplina escolar. Tese (doutorado em Educação) - Faculdade de Educação, Universidade de São Paulo, São Paulo, 2014.

NEVES, Clarissa Eckert Baeta. Estudos sociológicos sobre educação no Brasil. In: MICELI, Sérgio (org.). O que ler na ciência social brasileira: 1970-2002. V. IV. São Paulo: Sumaré; Brasília: CAPES, 2002, p. 351-437.

NOVAIS, Fernando Antônio; ARRUDA, Maria Arminda do Nascimento. Apresentação: revisitando os intérpretes do Brasil. Revista USP, São Paulo, n. 38, p. 8-9, jun./ago. 1998.

OLIVEIRA, Amurabi. Um balanço sobre o campo do ensino de Sociologia no Brasil. Em Tese, Florianópolis, v. 12, n. 2, p. 6-16, ago./dez. 2015.

PIERSON, Donald. Depoimentos de Donald Pierson. In: CORRÊA, Mariza. História da Antropologia no Brasil (1930-1960). Testemunhos: Emílio Willems, Donald Pierson. Campinas: Unicamp; São Paulo: Vértice, 1987, p. 29-116.

PIERSON, Donald. Difusão da ciência sociológica nas escolas. Sociologia, São Paulo, v. 11, n. 3, 1949. (Symposium sobre o Ensino de Sociologia e Etnologia).

PONTES, Heloísa. Destinos mistos: o "Grupo Clima" no sistema cultural paulista. Tese (doutorado em Sociologia) - Faculdade de Filosofia, Letras e Ciências Humanas, Universidade de São Paulo, São Paulo, 1996.

SANTOS, Mário Bispo dos. A Sociologia no contexto das reformas do ensino médio. In: CARVALHO, Lejeune Mato Grosso de (org.). Sociologia e ensino em debate: experiências e discussão de sociologia no ensino médio. Ijuí: Unijuí, 2004, p. 131-180.

SARANDY, Flávio Marcos Silva. O debate acerca do ensino de sociologia no secundário, entre as décadas de 1930 e 1950 . Ciência e modernidade no pensamento educacional brasileiro. Mediações, Londrina, v. 12, p. 67-94, 2007.

SAVIANI, Demerval. História das ideias pedagógicas no Brasil. 3. ed. Campinas: Autores Associados, 2010.

SCHWARCZ, Lilia Moritz. O nascimento dos museus brasileiros (1870-1910). In:

MICELLI, Sérgio (org.). História das Ciências Sociais no Brasil. v. 1. São Paulo: Sumaré, 
2001, p. 29-90.

SOARES, Jefferson da Costa. O ensino de Sociologia no Colégio Pedro II (1925-1941). 2009. Dissertação (Mestrado em Educação) - Faculdade de Educação, Universidade Federal do Rio de Janeiro, Rio de Janeiro, 2009.

SOCIOLOGIA. São Paulo, v. 1, n. 1, 1939.

SOCIOLOGIA. Symposium sobre o Ensino de Sociologia, São Paulo, v. 11, n. 3, 1949.

VILLAS-BÔAS, Gláucia Kruse. Apresentação. In: VILLAS-BÔAS, Gláucia (org.). A importância de dizer não e outros ensaios sobre a recepção da Sociologia em escolas cariocas. Rio de Janeiro: IFCS/UFRJ, 1998. (Série Iniciação Científica, n. 8).

WILLEMS, Emilio. Depoimentos de Emilio Willems. In: CORRÊA, Mariza. História da Antropologia no Brasil (1930-1960). Testemunhos: Emilio Willems, Donald Pierson. Campinas: Unicamp; São Paulo: Vértice, 1987, p. 117-127.

Recebido em agosto de 2021.

Aprovado em outubro de 2021. 